\title{
The roles of curcumin in regulating the tumor immunosuppressive microenvironment (Review)
}

\author{
YIZHI WANG, JUN LU, BOLUN JIANG and JUNCHAO GUO \\ Department of General Surgery, Peking Union Medical College Hospital, \\ Chinese Academy of Medical Sciences and Peking Union Medical College, Beijing 100730, P.R. China
}

Received September 13, 2019; Accepted January 22, 2020

DOI: $10.3892 / \mathrm{ol} .2020 .11437$

\begin{abstract}
Cancer is a harmful threat to human health. In addition to surgery, a variety of anticancer drugs are increasingly used in cancer therapy; however, despite the developments in multimodality treatment, the morbidity and mortality of patients with cancer patients are on the increase. The tumor-specific immunosuppressive microenvironment serves an important function in tumor tolerance and escape from immune surveillance leading to tumor progression. Therefore, identifying new drugs or foods that can enhance the tumor immune response is critical to develop improved cancer prevention methods and treatment. Curcumin, a polyphenolic compound extracted from ginger, has been shown to effectively inhibit tumor growth, proliferation, invasion, metastasis and angiogenesis in a variety of tumors. Recent studies have also indicated that curcumin can modulate the tumor immune response and remodel the tumor immunosuppressive microenvironment, indicating its potential in the immunotherapy of cancer. In this review, a brief introduction to the effects of curcumin on the tumor immune response and tumor immune microenvironment is provided and recent clinical trials investigating the potential of curcumin in cancer therapy are discussed.
\end{abstract}

\section{Contents}

1. Introduction

2. Anticancer effect of curcumin

3. The tumor immunosuppressive environment

4. The role of curcumin in tumor immunomodulation

5. Recent clinical trials on curcumin

6. Conclusions and future prospects

Correspondence to: Dr Junchao Guo, Department of General Surgery, Peking Union Medical College Hospital, Chinese Academy of Medical Sciences and Peking Union Medical College, 1 Shuaifuyuan Road, Dongcheng, Beijing 100730, P.R. China

E-mail: gjcpumch@163.com

Key words: curcumin, tumor suppressive immune environment, immune response, cytotoxic $\mathrm{T}$ cells, natural killer cell, clinical trials

\section{Introduction}

Cancer remains one of the diseases with a poor prognosis, which results in a high mortality rate (1). According to the 2019 American Cancer Annual Report, approximately $1,762,450$ new cases of cancer and 606,880 cancer-associated deaths were predicted in the United States in 2019, with no significant improvement compared with the previous year $(1,2)$. The prevalence of cancer and associated death statistics are also not optimistic in China; in 2015, 4,292,000 new cases of cancer were estimated and more than half of the cases were predicted to result in cancer-associated death in 2016 (3). Enormous economic burdens have been placed on nations and society in response to the increasing numbers of patients with cancer. For example, health care spending on patients with breast cancer in the United States has increased in recent years and the cost of treating patients with human epidermal growth factor receptor-2-positive breast cancer is predicted to rise from $\$ 2.7$ billion in 2012 to $\$ 3.6$ billion in 2035 (4). Therefore, cancer prevention and treatment is currently a major problem. Identifying natural food ingredients with low toxicity and minimal adverse side effects that can effectively target tumors may be valuable to cancer prevention and early treatment.

Curcumin, also known as diacetylmethane, is a bioactive lipophilic flavonoid polyphenol compound extracted from turmeric, the rhizome of the ginger family. Curcumin is an orange-yellow crystalline powder and its molecular weight is 368.38 (5). Curcumin is almost insoluble in water but soluble in ethanol and dimethyl sulfoxide (5). In addition to the use of curcumin as a food flavoring, curcumin has also been used in India and South Asia to treat a variety of diseases, including fever, gastrointestinal disorders, skin diseases, rheumatism, hepatitis, arthritis and burns due to its non-toxic, anti-oxidant, anti-inflammatory and anti-infection properties (6-9).

Previous findings have shown that curcumin also has significant anticancer effects. Curcumin has been shown to inhibit proliferation, invasion, metastasis and angiogenesis, weaken chemoresistance and inhibits the immortalization of cancer cells. Curcumin has been shown to modulate signaling pathways involving Janus kinase (JAK)/signal transducers and activators of transcription (STAT), phosphatidylinositol 3-kinase $(\mathrm{PI} 3 \mathrm{~K}) /$ protein kinase $\mathrm{B}(\mathrm{Akt}) / \mathrm{mammalian}$ target of rapamycin (mTOR), Wnt/ $\beta$-catenin, vascular endothelial growth factor (VEGF)/vascular endothelial growth factor 
receptor (VEGFR) and genes such as cyclin D1, TP53, BAX, $B C L-2, h T E R T$ and MMPs (10-14); these pathways have been confirmed to modulate the proliferation, migration and invasion, cell cycle and cell apoptosis of tumor cells (15-17).

During tumor progression, the tumor immunosuppressive microenvironment is considered to serve a crucial role in immune escape and subsequent progression of tumors (18). In addition to curcumin inhibiting tumors through the abovementioned mechanisms, curcumin also enhances the anticancer immune response, remodels the tumor immunosuppressive microenvironment and exerts influence on lymphocyte infiltration, such as cytotoxic T cells (CTL) (19), Foxhead p3 (FOXP3)+ regulatory T cells (FOXP3+Tregs) (20) and natural killer (NK) cells (21), and the M1 to M2 macrophage transformation in the process of innate immunity (22).

The present review briefly summarizes the important roles of curcumin in the treatment of tumors, with a focus on the functions of curcumin in tumor immunity regulation, and describes recent clinical trials investigating the potential of curcumin in cancer therapy.

\section{Anticancer effect of curcumin}

Curcumin can inhibit various malignant biological behaviors of tumor cells, including tumor proliferation and growth, invasion, metastasis, neoangiogenesis and chemoresistance, as summarized in Fig. 1.

Curcumin and tumor proliferation. Previous studies have shown that curcumin can regulate tumor proliferation and growth through multiple signal pathways $(10,23)$. Human trophoblastic surface antigen-2 (Trop2) is a cell surface glycoprotein, which serves an essential role in tumor progression and tumorigenesis (24). A recent study in bladder cancer showed that Trop2 abolished the increased expression of p27 caused by curcumin, thereby mediating tumor proliferation (25). Therefore, Trop2 may be an intermediate link in the inhibition of the tumor proliferation signal pathway by curcumin, with potential for therapeutic targets. However, curcumin has also been shown to inhibit pancreatic cancer cells proliferation through $\mathrm{p} 21$ or the $\mathrm{p} 27 /$ Cyclin D1/PI3K/Akt signaling pathway (26).

The Wnt/ $\beta$-catenin signaling pathway is involved in the mechanisms underlying the function of curcumin in hindering tumor growth and proliferation. Wang et al (27) and Srivastava and Srivastava (28) demonstrated that curcumin inhibits the proliferation of lung cancer cell lines. Wang et al (27) also demonstrated that curcumin inhibited tumor oxidative stress with subsequent inactivation of the $\mathrm{Wnt} / \beta$-catenin signaling pathway. Moreover, phosphorylation-mediated inactivation of the JAK2/STAT3 signaling pathway is also involved in the anti-proliferation effect of curcumin on osteosarcoma cells (29). Interestingly, in lung cancer, increased expression levels of long non-coding RNA (lncRNA) UCA1 counteracted the anticancer proliferation effects of curcumin, suggesting that lncRNA UCA1 may be involved in curcumin-mediated inactivation of Wnt and mTOR signaling pathways (30).

Curcumin and tumor apoptosis. Apoptosis is the process of programmed cell death that is caused by damage to DNA or other organelles, such as mitochondria and endoplasmic reticulum, when cells are externally stimulated (31). Apoptosis can be induced by several exogenous pathways, including pathways mediated by death receptor Fas and the tumor necrosis factor receptor family $(32,33)$, cytokine-mediated endogenous pathways and caspase-12 activation caused by endoplasmic reticulum stress (34). Curcumin is hypothesized to mediate tumor cell apoptosis through these exogenous pathways. Synthetic curcumin non-spherical mesoporous silica nanoparticles can increase the carrying capacity and saturability of curcumin (35). In-depth studies have shown that curcumin binds apoptotic proteins, such as caspase-3 (36), phosphatase and tensin homolog deleted from chromosome 10 and poly ADP-ribose polymerase (37), inducing mitochondrial damage and thereby promoting tumor cell apoptosis (35). Another synthetic nanomaterial, chitosan nanoparticles loaded with demethoxycurcumin in combination with cisplatin, downregulates the expression levels of thymidine phosphorylase required for DNA self-repairing pyrimidine salvage pathways and induces apoptosis in non-small cell lung cancer (NSCLC) cell lines (38). Moreover, Wang et al (27) demonstrated that in NSCLC, curcumin decreases the mitochondrial transmembrane potential and increases the accumulation of reactive oxygen species (ROS) in cells, inducing DNA and mitochondrial damage-mediated apoptosis (39).

Curcumin, tumor invasion and metastasis. The invasion and metastasis ability of tumor cells is a common cause of tumor treatment failure (40) and curcumin can significantly inhibit these activities in tumor cells. A study of oral squamous cell carcinoma showed that curcumin reduced cell adhesion and inhibited proliferation of tumor cells with mesenchymal features (41). In addition, tumor growth factor- $\beta 1$ (TGF- $\beta 1$ ) is an important promoter of the epithelial-mesenchymal transition (EMT) in tumor cells. In liver cancer, curcumin can decreased the expression levels of TGF- $\beta 1$, inhibit the phosphorylation and nuclear translocation of Smad2, reduce the specific binding of Smad2 to the Snail promoter, downregulate Snail expression levels and inhibit EMT by competing with TGF- $\beta 1$ (42). A moderate amount of ROS accumulation has been reported to be beneficial to tumor progression (43). Curcumin reversed the effect of $\mathrm{H}_{2} \mathrm{O}_{2}$ and ROS on pancreatic cancer cell invasion and metastasis by specifically inhibiting the extracellular regulated protein kinase (ERK)/nuclear factor kappa-B (NF-kB) signal pathway (44).

Curcumin and tumor neoangiogenesis. The growth of a solid tumor depends on tumor neovascularization (45). Angiogenic factors such as VEGF, hypoxia-inducible factor- $1 \alpha$, angiopoietin-1 and -2 and interleukin-2, -8 and -17 are closely associated with tumor neovascularization $(46,47)$. These factors can be modulated by curcumin to remodel tumor neovascularization. VEGF is a crucial target for curcumin to regulate tumor angiogenesiss (48). Curcumin inhibits the expression levels of VEGF, reduces its extracellular secretion and binds to the VEGF receptor, inhibiting the VEGF downstream signaling pathway (48). Curcumin can block hepatocyte growth factor induced EMT in lung cancer cell lines and the angiogenesis of human umbilical vein endothelial cells through targeting c-Met/PI3K/Akt/mTOR signaling 

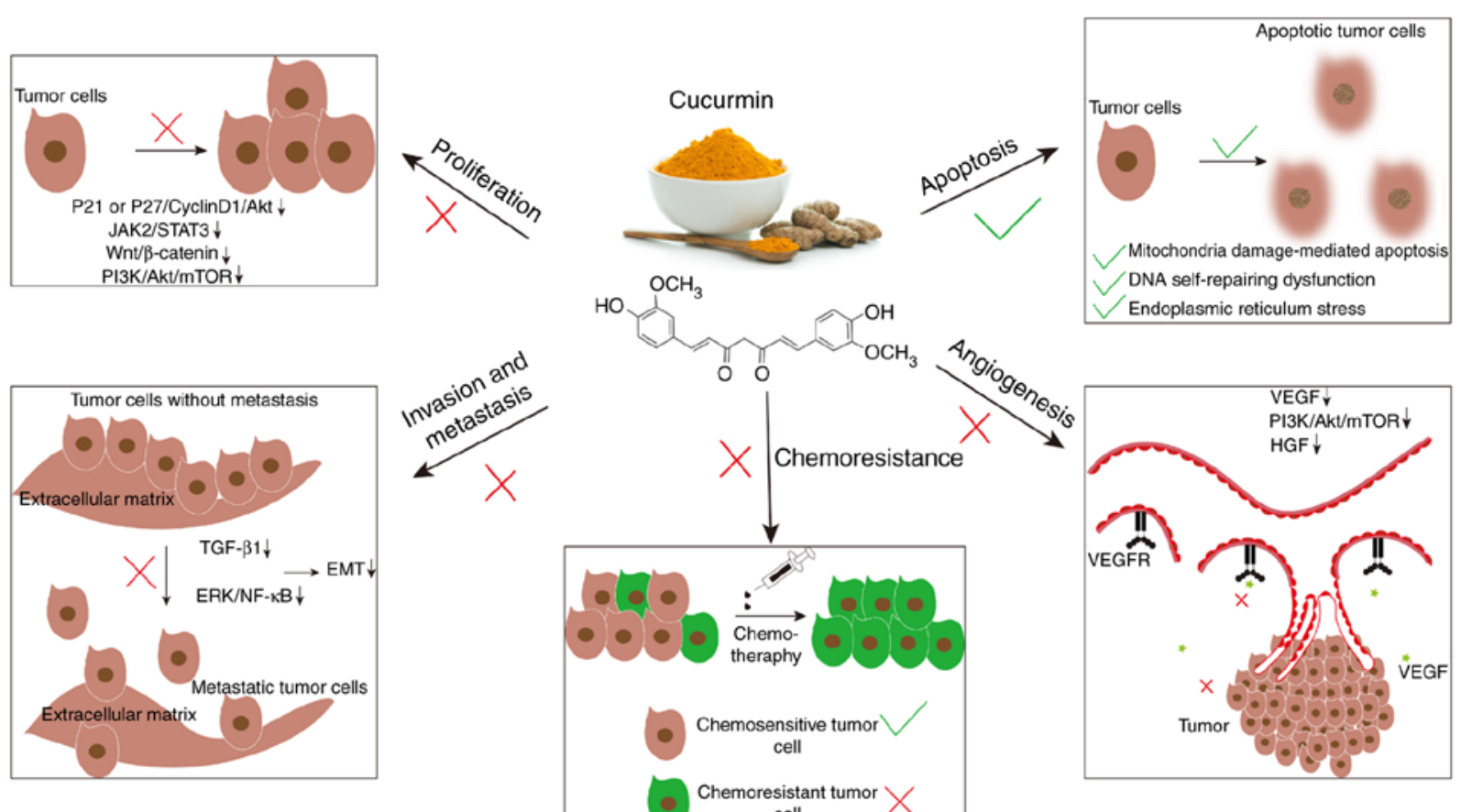

Figure 1. Curcumin exerts various effects on the malignant activities of tumor cells. Curcumin inhibits tumor cell proliferation through p21 or p27/CyclinD1/ PI3K/Akt, JAK2/STAT3, Wnt//-catenin and PI3K/Akt/mTOR signal pathways. Curcumin induces tumor cell apoptosis by mitochondria damage-mediated apoptosis, DNA self-repairing dysfunction and endoplasmic reticulum stress. Curcumin inhibits tumor cell EMT, which prevents tumor cell invasion and metastasis through downregulation of TGF- $\beta$ expression and inactivation of TGF- $\beta$ downstream signaling pathways. Neoangiogenesis is blocked by curcumin through decreasing the expression of VEGF and HGF, inactivating the PI3K/Akt/mTOR signaling pathway. Chemoresistance can be overcome by curcumin, which mediates cancer stem cell apoptosis. PI3K, phosphatidylinositol 3-kinase; Akt, protein kinase B; JAK2, Janus kinase 2; STAT3, signal transducer and activator of transcription 3; mTOR, mammalian target of rapamycin; TGF- $\beta 1$, tumor growth factor $\beta 1$; ERK, extracellular regulated protein kinase; NF- $\mathrm{kB}$, nuclear factor-k-gene binding; EMT, epithelial-mesenchymal transition; VEGF, vascular endothelial growth factor; VEGFR, vascular endothelial growth factor receptor; HGF, hepatocyte growth factor.

pathway, which indicated the anti-metastasis and anti-angiogenesis ability of curcumin in cancer treatment (49). The $\mathrm{PI} 3 \mathrm{~K} / \mathrm{Akt} / \mathrm{mTOR}$ signaling pathway is blocked by curcumin targeting c-Met, and curcumin abolishes the angiogenesis of human umbilical vein endothelial cells induced by hepatocyte growth factor.

Curcumin and tumor chemoresistance. The intrinsic resistance and adaptive resistance of tumors to chemotherapeutics are important reasons for chemotherapy failure (50). Therefore, identifying efficient chemotherapy sensitizers is important to address this problem. Curcumin has been demonstrated to exert specific functions in resensitizing certain types of cancer to chemotherapy, such as colorectal cancer and ovarian cancer. Chemotherapeutic drugs, such as irinotecan, 5-fluorouracil and capecitabine, show a decline in efficacy during colorectal cancer therapy and cancer stem cells (CSCs) are considered to influence this process (51). Curcumin increases the sensitivity of colon cancer cells to capecitabine by inducing apoptosis of CSCs (51). In addition, the combination of mitomycin $\mathrm{C}$ and curcumin downregulates the expression levels of anti-apoptotic proteins Bcl-2 and Bcl-w and induces the apoptosis of breast CSCs (52). Zhang et al (53) demonstrated that curcumin restores IncRNA MEG3 function in ovarian cancer cells and exosomal vesicles via demethylation, reduces the expression levels of miR-214, which can induce cell survival and cisplatin resistance through targeting the PTEN/Akt pathway (54).

\section{The tumor immunosuppressive environment}

The tumor microenvironment is complex and heterogeneous (55). O'Donnell et al (56) classified the tumor microenvironment into four types according to tumor mutation burden and the degree and subgroup of tumor infiltrating $\mathrm{T}$ cells. The different types of immune microenvironments, such as those that suppress and enhance the mivroenvironment, correspond to specific types of tumors and different tumor immunotherapeutics should be administrated according to the different types of immune microenvironment (56). Immunosuppressive cells in the tumor microenvironment can facilitate the progression of tumors through generating tumor immunosuppressive microenvironment (57). Previous research has suggested that in the early stage of tumors, both innate and adaptive immunity are active in immune surveillance, thereby suppressing spontaneous tumorigenesis, which is usually transient $(58,59)$. Tumor-associated antigens are considered to be a necessary component in stimulating the tumor immune response. Innate immune cells, such as dendritic cells (DCs) (59), macrophages and NK cells (21), recognize tumor-associated antigens and stimulate cytotoxic effects thereby killing the tumor cells. Moreover, antigen-presenting cells also present tumor-associated antigens to adaptive immune cells, such as CTLs or Th1 cells, to stimulate specific killing pathways against tumor cells (19). If a tumor is regenerated, the memory of adaptive immunity can exert the same killing effect (60). However, the mechanisms in vivo are 
A

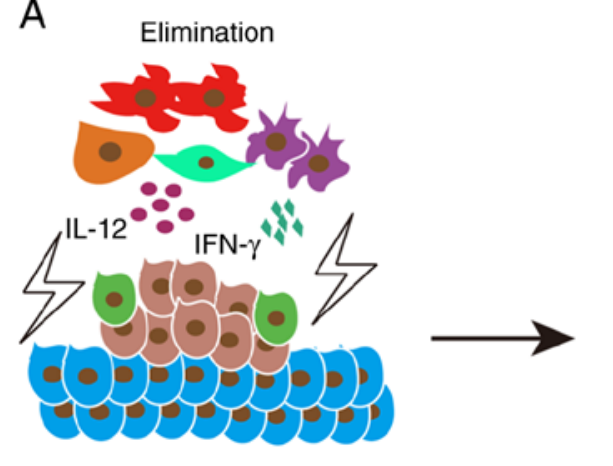

B

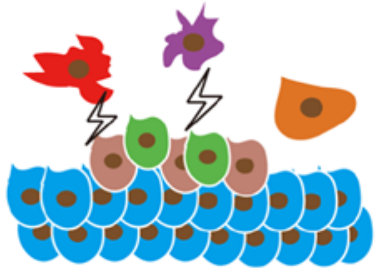

Equilibrium

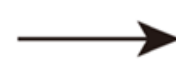

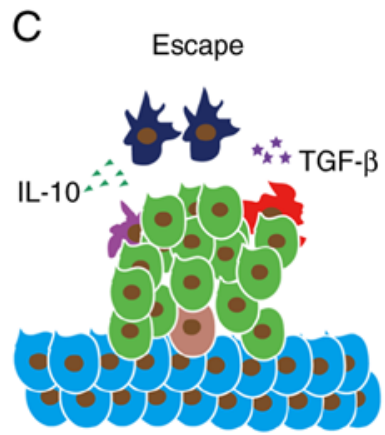

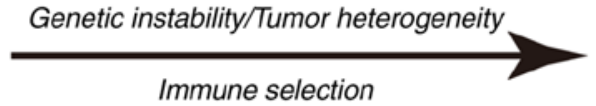

\begin{tabular}{lll}
\hline Normal cells \\
Tumor cells \\
Low immunogenic \\
tumor cells \\
CD4+T cells
\end{tabular}$\gamma \delta \mathrm{T}$ cells

Figure 2. The three 'E's of cancer immunoediting. (A) Elimination: IFN- $\gamma$, IL-12 and other tumor suppressive cytokines are released by NK cells and $\gamma \delta T$ cells mediate perforin, granzyme, FasL and TraiL-dependent cytotoxic effects in the early stage of tumor progression. Antigen-presenting cells present tumor-specific antigens to CD4+T cells, thereby recruiting specific CD8+ T cells to further kill tumor cells. (B) Equilibrium: Adaptive immunity prevents tumors from continuing to grow and confers immunogenicity to tumor cells to mediate immune recognition. Tumor cells can also block the constant immune system killing mechanism by gene mutations, which confer the ability of some tumor cells to escape from immune recognition. Therefore, tumor cells and the immune system reach an equilibrium state. (C) Escape: Tumor cells regulate the immune response of T cells and promote their apoptosis through releasing immunosuppressive cytokines, such as TGF- $\beta$ and IL-10. In addition, increased intratumoral infiltration of CD4+CD25+FOXP3+Treg cells upregulates TGF- $\beta$ and IL-10 expression levels and downregulates IL-2 expression levels. IFN, interferon; IL, interleukin; NK cells, natural killer cells; TGF- $\beta$, tumor growth factor $\beta$; Treg, regulatory $\mathrm{T}$ cell.

more complex. First, tumor cells mediate immune escape by altering the composition of tumor infiltrating immune cells by recruiting multiple immunosuppressive cytokines, which induce increased production of Treg cells, antigen-tolerant M2 macrophages and DCs, and reducing the infiltration of CTLs, NK cells and NKT cells, resulting in loss of tumor immune surveillance function (61). Second, tumor-associated antigens can be non-tumor-specific and normal cells occasionally also produce the same antigen, mediating innate immune tolerance and leading to dysfunction of immune system recognition of tumor-associated antigens (62). Third, the lack of major histocompatibility complex class I on the surface of tumor cells can lead to the inability of the immune recognition of CD8+ cytotoxic $T$ cells to mediate immune tolerance (63). In addition, upregulated expression of immunosuppressive ligands, such as programmed cell death-ligand 1, also mediates tumor immune tolerance (64). Subsequently, the immune cells in both innate and adaptive immunity become apoptotic due to the lack of stimulation of tumor-associated antigens and the inability to specifically recognize tumor cells, leading to the immune escape of tumors $(65,66)$.

In addition, post-transcriptional modifications of some tumor-specific antigen genes, such as GIL1 in multiple myeloma (67) and hPMS1 in oral squamous cell carcinoma (68), may result in their downregulated expression or complete silencing. The cancer-testis family is expressed on a variety of cell surfaces and hypomethylation of the cancer-testis family promoter facilitates gene expression and thus expression on the tumor cell surface; however, in contrast, demethylation of this promotor occurs in tumor cells mediating tumor immune tolerance (69). DNA methyltransferase or histone deacetylase activity can restore the gene expression of tumor-specific antigens to a certain degree, mediating anticancer immunity (70,71). However, Rosenthal et al (72) indicated that hypermethylation of gene promoters of mutant neoantigens was also a possible mechanism leading to tumor immunoediting in early stage NSCLC.

Increasing studies have shown that the interaction between the immune microenvironment and tumor cells is a process of dynamic equilibrium, which was called immunoediting by Dunn et al (73). Immunoediting is the entire process of editing and shaping the immunosuppressive microenvironment and is also a Darwinian selection process. Immunoediting consists of three phases: Elimination (also called immunosurveillance); equilibrium (also called cancer dormancy); and escape and collectively these are referred to as the 3 'E's' of immune editing (73). In the first phase, a growing tumor recruits innate immune cells such as NK cells and $\gamma \delta \mathrm{T}$ cells, which mediate perforin, granzyme, FasL and TraiL-dependent cytotoxic effects through releasing interferon- $\gamma$ (IFN- $\gamma$ ), 

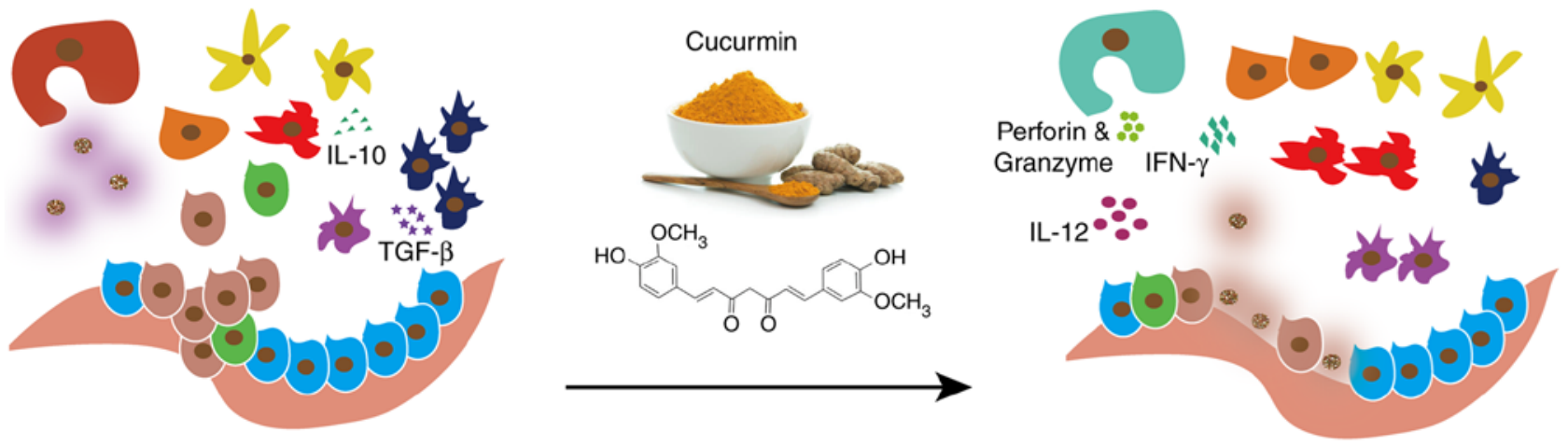

$\checkmark$ Upregulating the infiltrtion of cytotoxic T cells and downregulating the infiltration of Treg by NF-kB activity and inactivating TNF- $\alpha$ signaling pathway

$\checkmark$ Enhancing the function of effector T cell by elevating the expression of IFN- $\gamma$

$\checkmark$ Modulating the function and expression of IL-2, IL-6, IL-12 and IFN- $\gamma$

$\checkmark$ Intensifing the cytotoxic of NK cells through impairment of ubiquitin-proteasome system, activating stat4, stat5 and PI3K/Erk signaling pathway

$\checkmark$ Mediating the transformation of M2 into M1 TAMs

\begin{tabular}{|ll|}
\hline Normal cells & Apoptosis T cells \\
Tumor cells & NK cells \\
Low immunogenic & M2 TAM \\
tumor cells & Mature DCs \\
CD4+T cells & M1 TAM
\end{tabular}

Figure 3. The role of curcumin in tumor immunomodulation. The shaping of the tumor immunosuppressive microenvironment is induced by tumor cell secretion of immunosuppressive cytokines, such as IL-10 and TGF- $\beta$, apoptosis and malfunction of effector T cells and the infiltration of Treg cells. Curcumin remodels the tumor immunosuppressive microenvironment by: Regulating the infiltration of cytotoxic $\mathrm{T}$ cells and Treg by restoring NF- $\mathrm{BB}$ activity, inactivating the TNF- $\alpha$ signaling pathway; enhancing effector T cells function by elevating the expression of IFN- $\gamma$; modulating the function and expression of cytokines; increasing the generation of NK cells through impairment of the ubiquitin-proteasome system, activating STAT4, STAT5 and PI3K/Erk signaling pathway; and mediating the transformation of M2 TAMs into M1 TAMs. Treg, regulatory T cell; NK cells, natural killer cells; DCs, dendritic cells; TAM, Tumor-associated macrophage; TGF- $\beta$, Tumor growth factor $\beta$; IL, Interleukin; IFN, interferon.

IL-12 and other tumor suppressive cytokines $(74,75)$. In addition, antigen-presenting cells present tumor-specific antigens to CD4+T cells thereby recruiting specific CD8+ $\mathrm{T}$ cells to kill tumor cells (76). In the second phase, adaptive immunity, rather than innate immunity, prevents tumors from continuing to grow and confers immunogenicity to tumor cells to mediate immune recognition (77). Tumor cells hijack the various mechanisms mentioned above to inhibit the immune system killing mechanisms allowing some of the less immunogenic tumor cells to survive (77). In addition, tumor cell instability caused by gene mutations also confers the ability of some tumor cells to escape from immune recognition (78). Thus, tumor cells and the immune system can reach an equilibrium state, and tumor proliferation and tumor apoptosis also reach an equilibrium state (77). This balancing process may be inclined toward tumor cell elimination or tumor cell escape depending on the progression of tumor and may last for months to years (79). In the third phase, the tumor further grows and becomes a clinically detectable tumor, which gradually suppresses the immune system and shapes the immunosuppressive microenvironment (80). Tumor cells regulate the immune response of $\mathrm{T}$ cells and promote their apoptosis through releasing immunosuppressive cytokines, such as TGF- $\beta$, IL-10, galectin and indole 2,3-dioxygenase (81). In addition, intratumoral infiltration of CD4+CD25+FOXP3+Tregs in tumor cells increases TGF- $\beta$ and IL-10 expression levels, IL-2 expression level knockdown, and reduces co-stimulation and activation of DCs (82). The three phases of immune editing ultimately lead to the immune escape of tumor cells as summarized in Fig. 2.

\section{The role of curcumin in tumor immunomodulation}

Curcumin not only inhibits tumors by affecting the biological behaviors of tumor cells, but it also regulates the composition of different components in the tumor immune microenvironment, so that the immune microenvironment is conducive to tumor killing (83). The detailed roles of curcumin in tumor immunomodulation are shown in Fig. 3.

Curcumin regulates the number of various infiltrating $T$ cells. In the tumor immunosuppressive microenvironment, due to the lack of effective presentation of tumor-specific antigens and the influence of various inhibitory cytokines, a large number of inactivated CD4+ and CD8+ T cells and CTLs undergo apoptosis (78). Curcumin has been shown to effectively reverse this process. During tumor generation, tumor cells can induce atrophy of the thymus, reduce the 
production of mature $\mathrm{T}$ cells and enable escape from the adaptive immune response. Tumor cells induce apoptosis of $\mathrm{T}$ cells by interfering with the production of NF- $\mathrm{\kappa B}$ in $\mathrm{T}$ cells, making T cells susceptible to TNF- $\alpha$-mediated apoptosis (84). Curcumin neutralizes oxidative stress of tumor cells, restores $\mathrm{NF}-\kappa \mathrm{B}$ activity and reactivates the TNF- $\alpha$ signal pathway, thereby enhancing the ability of T cells to resist apoptosis (84). Bhattacharyya et al (84) found that mechanisms of tumor cell immune escape included loss of effector $\mathrm{T}$ cells and memory $\mathrm{T}$ cell subsets, secretion of type II cytokines and increased proliferation of Treg cells. In Ehrlich's ascites carcinoma-bearing nude mice treated with curcumin, curcumin inhibited the apoptosis of $\mathrm{T}$ cells, expanded the number of central memory cells and effector memory $\mathrm{T}$ cells and disabled the functions of Treg cells, thus successfully reversing the tumor immunosuppressive microenvironment (84). A clinical trial also demonstrated that in patients with colon cancer, transcription and expression of the FOXP3 gene was inhibited by curcumin, thereby permitting the conversion of FOXP3+Treg cells into Th1 cells (85). Curcumin also abolished the induction of IFN- $\gamma$ secretion from CD4+ T cells by inhibiting Treg cell function (85). Zou et al (86) also demonstrated the inhibition of Treg function by curcumin in lung cancer.

Curcumin enhances the function of effector $T$ cells. The effect of curcumin on $\mathrm{T}$ cells not only increases the number of effector $\mathrm{T}$ cells or to induce the infiltration of Treg cells, but more importantly, enhances the cell killing function of effector T cells inhibited by tumor cells (87). A novel nanocurcumin significantly increased the expression levels of co-stimulatory molecule CD86 on the surface of DCs and decreased the levels of pro-inflammatory factors secreted by effector $\mathrm{T}$ cells in vitro (87). Moreover, curcumin was also reported to increased effector $\mathrm{T}$ cell-induced cytotoxicity against esophageal cancer cells (87). Adoptive T-cell therapy has become an important research field of tumor immunotherapy. Autologous reinfusion of effector $\mathrm{T}$ cells, which proliferate in vitro, can increase the number of exogenous effector $\mathrm{T}$ cells and induce tumor apoptosis in humans (88). However, due to the numerous immunosuppressive cytokines in the tumor immunosuppressive microenvironment, the efficacy of adoptive T-cell therapy is often transient and prone to failure (89). In the E.G7 mouse T lymphoma model, the combination of adaptive T-cell therapy and curcumin led to increased intratumoral infiltration of CD8+ T cells at the end of the course and curcumin increased the levels of IFN- $\gamma$ secreted by CD8+T cells (90). These results showed that combination therapy had greater efficacy compared with adaptive T-cell therapy alone. Different doses of curcumin were administered to mice bearing tumors derived from the 3LL breast cancer cell line and a low dose of curcumin led to delayed tumor growth and prolonged survival of the mice. An in vitro study also demonstrated that low doses of curcumin increased the number of $\mathrm{CD} 8+\mathrm{T}$ cells and enhanced their IFN- $\gamma$ secretion capacity (91). Administration of high doses of curcumin, however, reduced the number of $\mathrm{CD} 8+\mathrm{T}$ cells, indicating that the anti-tumor effect of curcumin may be dose-dependent (91). Moreover, the combination of an intravenously administered polyethylene glycol curcumin coupler, rather than an oral formulation, and a tyrosinase-related peptide vaccine for the treatment of mela- noma significantly increased the CTL response and IFN- $\gamma$ expression levels compared with the vaccine alone, while the combination therapy also decreased the levels of tumor immunosuppressive cells, such as marrow-derived suppressor cells and Treg cells (92).

Curcumin modulates the function of cytokines. During the gradual shaping of the tumor immunosuppressive microenvironment, various cytokines are considered to serve a crucial role in regulating the composition and proportions of the cancer-promoting immune cell component and the cancer-suppressing immune cell component (93). Curcumin, as a tumor inhibitor, not only facilitates the secretion of cancer-promoting cytokines, but also inhibits the secretion of cancer-suppressing cytokines, thereby remodeling the tumor immunosuppressive microenvironment (94). IL-2 plays a dual role, stimulating and inhibiting the tumor immune response. Since high-affinity IL-2 receptor (IL-2R) is highly expressed on the surface of Treg cells, IL-2 is a tumor promoter activating Treg cells (95). Curcumin directly inhibits the interaction between IL-2 and IL-2R $\alpha$ (CD25), thus inhibiting the activation of Treg cells (96). A previous study reported that curcumin inhibits tumor cell apoptosis by downregulating the levels of the tumor immunosuppressive cytokine IL-10, resulting in JAK/STAT signal pathway malfunction (97). Curcumin also downregulates the levels of TGF- $\beta$ and IL-10 in Treg cells, reduces their ability to stimulated Treg cells and decreases the Treg cell infiltration in tumors (86). An increased expression level of IL-6 in triple-negative breast cancer is considered to mediate the tumor immunosuppressive microenvironment, leading to tumor vaccine therapy failure (98). Curcumin is a specific inhibitor of IL-6, and the combination of curcumin and breast cancer vaccine Listeriaat-Mage-b resulted in decreased IL-6 expression levels and increased IL-12 and IFN- $\gamma$ levels, resulting in greater anti-tumor efficacy compared with using vaccine alone (99). However, Bill et al (100) showed different results. Although previous reports showed that curcumin promoted tumor apoptosis (36-38), curcumin-pretreated human A375 melanoma cells led to STAT1 phosphorylation inhibition and decreased downstream IFN- $\gamma$ and IFN- $\alpha$ expression levels. In addition, co-culture of NK cells and these curcumin-pretreated melanoma cells also reduced IL-12-induced IFN- $\gamma$ expression, which indicated curcumin may also inhibit the expression of cancer-suppressing cytokines.

Curcumin intensifies the cytotoxicity of NK cells. Curcumin not only influences adaptive immunity through regulating $\mathrm{T}$ cell proliferation and apoptosis, but it also influences NK cell-mediated innate immunity (101). In a study of breast cancer, exosomes secreted by tumor cells abolished the activation of NK cells via IL-2 by inhibiting the JAK3/STAT5 signal pathway (102). Curcumin may inhibit the cytotoxicity of exosomes to circulating immune cells by disrupting the ubiquitin protease system and increasing the ubiquitinated exosomal proteins that interfere the function of normal exosomal proteins (102). Another study in breast cancer showed that curcumin increased the expression of CD16+ and CD56 $6^{\mathrm{dim}}$ on the surface of NK-92 cells (103). In addition, the effect of curcumin on promoting cytotoxic ability of NK cells 


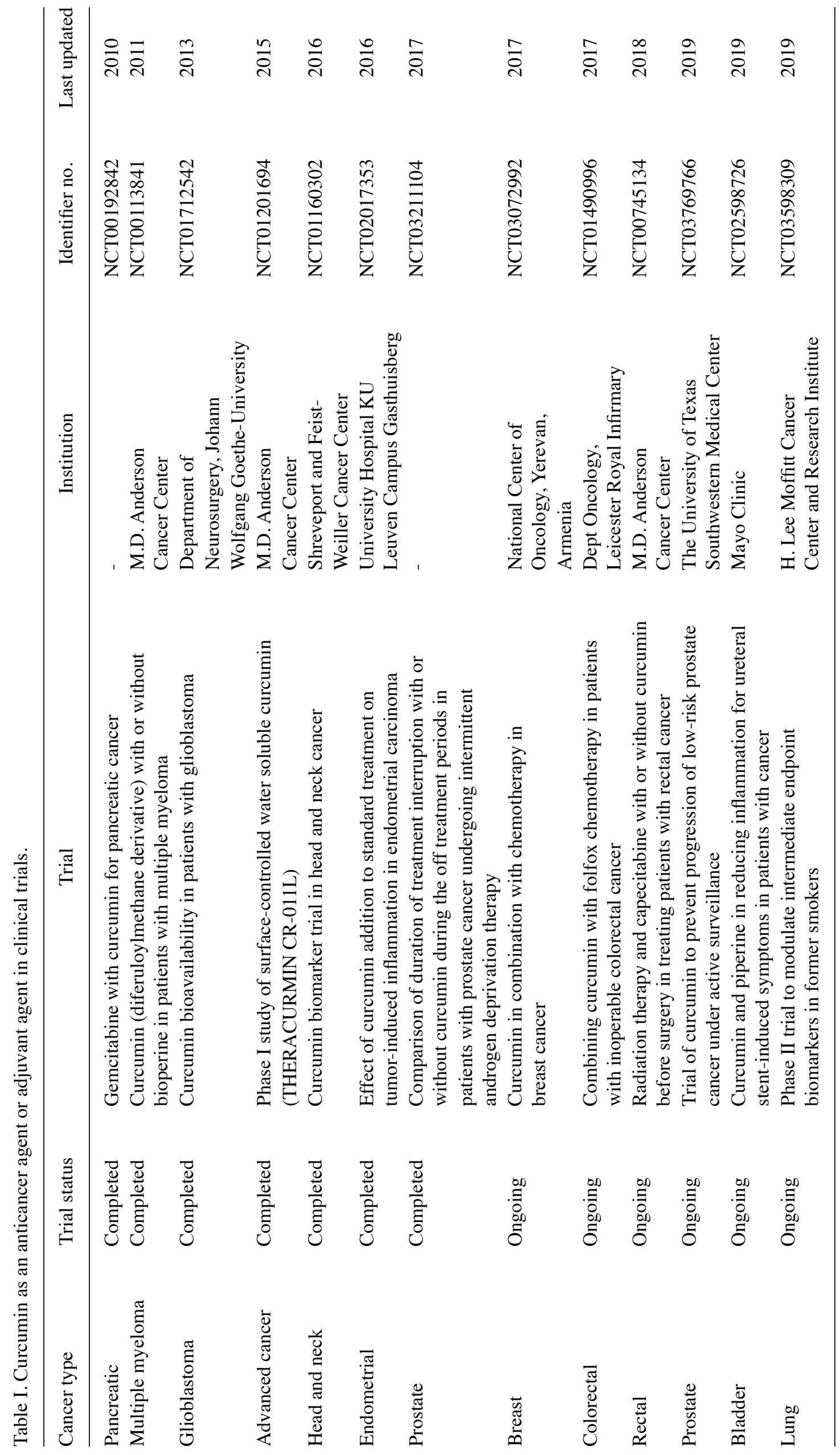


is also associated with the activation of STAT4 and STAT5 in NK cells and the suppression of pERK and PI3K expression in curcumin-induced breast cancer cells (103). In a study of pancreatic cancer, curcuminoids enhanced the ability of NK cells to secrete IFN- $\gamma$ and promoted the killing effect of NK cells in pancreatic cancer cell lines (104).

Curcumin mediates the transformation of M2 into M1 macrophages. Tumor-associated macrophages (TAMs) are classified into inducible nitric oxide synthase (NOS) (+) M1 macrophages and ARG1 (+) M2 macrophages according to their function following a strict binary classification, which was proposed by Mills et al (105). The former exhibit tumor-suppressing functions while the latter show tumor-promoting ability. M1 TAMs show high expression levels of IL-12 and low expression levels of IL-10, whereas M2 TAMs exhibit the opposite expression (106). In a study of HPV+ tumors, injection of TriCurin, a synergistic formulation of curcumin, resveratrol and epicatechin gallate into tumor-bearing mice transformed $\mathrm{ARG}^{\text {high }}, \mathrm{IL}-10^{\text {high }}, \mathrm{iNOS}^{\text {low }}, \mathrm{IL}-12^{\text {low }}$ M2 TAMs into ARG ${ }^{\text {low }}$, IL-10 ${ }^{\text {low }}$, iNOS $^{\text {high }}$, IL-12 ${ }^{\text {high }}$ M1 TAMs. Subsequently, M1 TAMs induced STAT1 and NF- $\mathrm{BB}$ (p65) expression, subsequently increasing the expression levels of IL-12 and thereby activating NK cells and CTLs, resulting in cytotoxicity (107). The same mechanism of action was also demonstrated in malignant glioma $(108,109)$.

\section{Recent clinical trials on curcumin}

Since 1987, when Kuttan et al (110) first conducted a clinical trial of curcumin for the treatment of external cancerous cancer, several clinical trials of curcumin alone or in combination with other cancer therapeutics have been widely carried out. At present, randomized, controlled, double-blind clinical trials of curcumin are mainly concentrated on pancreatic cancer (111), colorectal cancer (112), prostate cancer (113) and breast cancer (114), whereas clinical trials for other tumors are currently underway. Curcumin is being investigated in clinical trials of pancreatic cancer as a chemosensitizer because of the very low response rate $(<10 \%)$ of pancreatic cancer to traditional chemotherapeutic drugs and targeted drugs, such as gemcitabine and erlotinib (115). As early as 2008, a clinical trial of 25 patients with advanced pancreatic cancer showed that despite the low bioavailability rate of the curcumin oral formulation, the formulation can be tolerated and had good clinical biological activity in several patients (116). One of the patients had a progression-free survival of $>18$ months, which was longer compared the longest survival (12 months) in the prior study (115). In addition, administrating curcumin significantly downregulated the expression levels of $\mathrm{NF}-\kappa \mathrm{B}$, cyclooxygenase and phosphorylated STAT3 in peripheral blood mononuclear cells (116). By contrast, in another study, 17 patients with unresectable pancreatic cancer were administered oral curcumin $(8 \mathrm{~g} / \mathrm{d})$ and intravenous gemcitabine, but the results were unsatisfactory due to severe abdominal discomfort and abdominal pain caused by the oral curcumin formulation (117). However, in another later phase I/II clinical trial, the same oral dose of $8 \mathrm{~g}$ of curcumin combined with gemcitabine resulted in a median survival of 161 days for pancreatic cancer patients and a 1-year survival rate of $19 \%$ and most patients were able to tolerate this dose without serious adverse effects (118). Therefore, an oral dose of $8 \mathrm{~g} / \mathrm{d}$ curcumin is considered as a chemosensitization dose for pancreatic cancer.

To address the low bioavailability of curcumin, a recent clinical trial investigated the combination of phospholipid-coated curcumin using nanotechnology and gemcitabine (111). Although the patient quality of life was not significantly improved during treatment, the patient drug response rate reached $27.3 \%$, which was higher compared with the rate of $12 \%$ of gemcitabine alone, and the average progression-free survival and overall survival also reached 8.4 and 10.2 months, respectively (111). Therefore, curcumin combined with gemcitabine is may be a safe and effective therapy for wider application for pancreatic cancer treatment; however, before the combination of curcumin and gemcitabine therapy can become routine therapy for pancreatic cancer large multicentric randomized controlled trials need to be conducted. The recent ongoing and completed clinical trials of curcumin in diverse tumors are summarized in Table I by referring to clinicaltrials.gov.

\section{Conclusions and future prospects}

Curcumin, a traditional food ingredient, has been identified to serve versatile roles in the prevention and treatment of several diseases (119-121). Curcumin has also been identified to inhibit a variety of biological functions of tumors, including growth, proliferation, invasion, metastasis, apoptosis, angiogenesis and drug resistance of tumor cells (122). In the present review, highlighted the role of the tumor immunosuppressive microenvironment in tumor progression and the functions of curcumin in modulating and remodeling the tumor immunosuppressive microenvironment have been highlighted. Curcumin increases the number of effector $\mathrm{T}$ cells (78), reduces the infiltration of FOXP3+Tregs (85), inhibits cytokine-induced apoptosis of effector T cells and the expression of tumor immunosuppressive cytokines $(87,94)$, enhances NK cell cytotoxicity and mediates M2 TAM transformation to M1 TAM $(101,105)$, which can change the tumor immunosuppressive microenvironment and lead to the killing of tumor cells. Therefore, given the multiple functions and good biosafety of curcumin in inhibiting tumor progression, as a tumor-preventing food and tumor-assisted therapeutic drug, curcumin has potential in tumor treatment potential in combination with multimodal anticancer therapies. However, curcumin has several limitations in clinical practice such as its low bioavailability, drug dose-effect disproportion and poor water solubility (123). To address these problems, an increasing numbers of studies are focusing on how to enhance the tolerance of curcumin, improve the targeting of curcumin delivery, overcome low bioavailability and obtain better therapeutic effects $(124,125)$. A variety of nano-curcumin formulations have been introduced, which have improved the anti-cancer effects of curcumin $(126,127)$. It is considered that curcumin will serve a more important role in the prevention and treatment of cancer in the future.

\section{Acknowledgements}

Not applicable. 


\section{Funding}

The present study was supported by The China Academy of Medical Sciences Innovation Fund for Medical Sciences (grant no. 2016-I2M-3-019).

\section{Availability of data and materials}

Not applicable.

\section{Authors' contributions}

In this review, the concept and design was conducted by YW and JG. YW and JL drafted the manuscript. Tables and diagrams were generated by JL and BJ. Critical revision of the manuscript for important intellectual content was conducted by YW, JL and BJ. JG provided the funding support. All authors read and approved the final manuscript.

\section{Ethics approval and consent to participate}

Not applicable.

\section{Patient consent for publication}

Not applicable.

\section{Competing interests}

The authors declare that they have no competing interests.

\section{References}

1. Siegel RL, Miller KD and Jemal A: Cancer statistics, 2018. CA Cancer J Clin 68: 7-30, 2018.

2. Siegel RL, Miller KD and Jemal A: Cancer statistics, 2019. CA Cancer J Clin 69: 7-34, 2019.

3. Chen W, Zheng R, Baade PD, Zhang S, Zeng H, Bray F, Jemal A, Yu XQ and He J: Cancer statistics in China, 2015. CA Cancer J Clin 66: 115-132, 2016.

4. Tartari F, Santoni M, Pistelli M and Berardi R: Healthcare cost of HER2-positive and negative breast tumors in the United States (2012-2035). Cancer Treat Rev 60: 12-17, 2017.

5. Maheshwari RK, Singh AK, Gaddipati J and Srimal RC: Multiple biological activities of curcumin: A short review. Life Sci 78: 2081-2087, 2006.

6. Jin TR: Curcumin and dietary polyphenol research: Beyond drug discovery. Acta Pharmacol Sin 39: 779-786, 2018.

7. Sa G and Das T: Anti cancer effects of curcumin: Cycle of life and death. Cell Div 3: 14, 2008.

8. Saha S, Adhikary A, Bhattacharyya P, Das T and Sa G: Death by design: Where curcumin sensitizes drug-resistant tumours. Anticancer Res 32: 2567-2584, 2012.

9. Aggarwal BB and Harikumar KB: Potential therapeutic effects of curcumin, the anti-inflammatory agent, against neurodegenerative, cardiovascular, pulmonary, metabolic, autoimmune and neoplastic diseases. Int J Biochem Cell Biol 41: 40-59, 2009.

10. Choudhuri T, Pal S, Das T and Sa G: Curcumin selectively induces apoptosis in deregulated cyclin D1-expressed cells at G2 phase of cell cycle in a p53-dependent manner. J Biol Chem 280: 20059-20068, 2005

11. Kunnumakkara AB, Anand P and Aggarwal BB: Curcumin inhibits proliferation, invasion, angiogenesis and metastasis of different cancers through interaction with multiple cell signaling proteins. Cancer Lett 269: 199-225, 2008.

12. Wang JB, Qi LL, Zheng SD and Wu TX: Curcumin induces apoptosis through the mitochondria-mediated apoptotic pathway in HT-29 cells. J Zhejiang Univ Sci B 10: 93-102, 2009.
13. Lee JH and Chung IK: Curcumin inhibits nuclear localization of telomerase by dissociating the Hsp90 co-chaperone p23 from hTERT. Cancer Lett 290: 76-86, 2010.

14. Shehzad A and Lee YS: Molecular mechanisms of curcumin action: Signal transduction. Biofactors 39: 27-36, 2013.

15. Bagratuni T, Mavrianou N, Gavalas NG, Tzannis K, Arapinis C, Liontos M, Christodoulou MI, Thomakos N, Haidopoulos D, Rodolakis A, et al: JQ1 inhibits tumour growth in combination with cisplatin and suppresses JAK/STAT signalling pathway in ovarian cancer. Eur J Cancer 126: 125-135, 2020.

16. Su T, Huang L, Zhang N, Peng S, Li X, Wei G, Zhai E, Zeng Z and $\mathrm{Xu}$ L: FGF14 functions as a tumor suppressor through inhibiting $\mathrm{PI} 3 \mathrm{~K} / \mathrm{AKT} / \mathrm{mTOR}$ pathway in colorectal cancer. J Cancer 11: $819-825,2020$

17. Rebouissou S and Nault JC: Advances in molecular classification and precision oncology in hepatocellular carcinoma. J Hepatol 72: 215-229, 2020.

18. Vinay DS, Ryan EP, Pawelec G, Talib WH, Stagg J, Elkord E, Lichtor T, Decker WK, Whelan RL, Kumara HMCS, et al: Immune evasion in cancer: Mechanistic basis and therapeutic strategies. Semin Cancer Biol 35 (Suppl): S185-S198, 2015.

19. Mukherjee S, Hussaini R, White R, Atwi D, Fried A, Sampat S, Piao L, Pan Q and Banerjee P: TriCurin, a synergistic formulation of curcumin, resveratrol, and epicatechin gallate, repolarizes tumor-associated macrophages and triggers an immune response to cause suppression of HPV+ tumors. Cancer Immunol Immunother 67: 761-774, 2018.

20. Bahrami A, Fereidouni M, Pirro M, Bianconi V and Sahebkar A: Modulation of regulatory T cells by natural products in cancer. Cancer Lett 459: 72-85, 2019.

21. Pan P, Huang YW, Oshima K, Yearsley M, Zhang J, Arnold M, $\mathrm{Yu} \mathrm{J}$ and Wang LS: The immunomodulatory potential of natural compounds in tumor-bearing mice and humans. Crit Rev Food Sci Nutr 59: 992-1007, 2019.

22. Schnekenburger M, Dicato M and Diederich MF: Anticancer potential of naturally occurring immunoepigenetic modulators: A promising avenue? Cancer 125: 1612-1628, 2019.

23. Sun XD, Liu XE and Huang DS: Curcumin induces apoptosis of triple-negative breast cancer cells by inhibition of EGFR expression. Mol Med Rep 6: 1267-1270, 2012.

24. McDougall AR, Tolcos M, Hooper SB, Cole TJ and Wallace MJ: Trop2: From development to disease. Dev Dyn 244: 99-109, 2015.

25. Zhang L, Yang G, Zhang R, Dong L, Chen H, Bo J, Xue W and Huang Y: Curcumin inhibits cell proliferation and motility via suppression of TROP2 in bladder cancer cells. Int J Oncol 53: 515-526, 2018

26. Zhao Z, Li C, Xi H, Gao Y and Xu D: Curcumin induces apoptosis in pancreatic cancer cells through the induction of forkhead box O1 and inhibition of the PI3K/Akt pathway. Mol Med Rep 12: 5415-5422, 2015

27. Wang JY, Wang X, Wang XJ, Zheng BZ, Wang Y, Wang X and Liang B: Curcumin inhibits the growth via Wnt/ $\beta$-catenin pathway in non-small-cell lung cancer cells. Eur Rev Med Pharmacol Sci 22: 7492-7499, 2018.

28. Srivastava NS and Srivastava RAK: Curcumin and quercetin synergistically inhibit cancer cell proliferation in multiple cancer cells and modulate Wnt/ $\beta$-catenin signaling and apoptotic pathways in A375 cells. Phytomedicine 52: 117-128, 2019.

29. Sun Y, Liu L, Wang Y, He A, Hu H, Zhang J, Han M and Huang Y: Curcumin inhibits the proliferation and invasion of MG-63 cells through inactivation of the $\mathrm{p}-\mathrm{JAK} 2 / \mathrm{p}-\mathrm{STAT} 3$ pathway. Onco Targets Ther 12: 2011-2021, 2019.

30. Wang WH, Chen J, Zhang BR, Lu SJ, Wang F, Peng L, Dai JH and Sun YZ: Curcumin inhibits proliferation and enhances apoptosis in A549 cells by downregulating lncRNA UCA1. Pharmazie 73: 402-407, 2018.

31. Elmore S: Apoptosis: A review of programmed cell death. Toxicol Pathol 35: 495-516, 2007.

32. Sato Y, Yoshino H, Tsuruga E and Kashiwakura I: Fas ligand enhances apoptosis of human lung cancer cells cotreated with RIG-I-like receptor agonist and radiation. Curr Cancer Drug Targets: Jan 15, 2020 (Epub ahead of print).

33. Lee KC, Lee KF, Tung SY, Huang WS, Lee LY, Chen WP, Chen CC, Teng CC, Shen CH, Hsieh MC and Kuo HC: Induction apoptosis of erinacine a in human colorectal cancer cells involving the expression of TNFR, fas, and fas ligand via the $\mathrm{JNK} / \mathrm{p} 300 / \mathrm{p} 50$ signaling pathway with histone acetylation. Front Pharmacol 10: 1174, 2019. 
34. Mortezaee K, Salehi E, Mirtavoos-Mahyari H, Motevaseli E, Najafi M,Farhood B, Rosengren RJ and Sahebkar A: Mechanisms of apoptosis modulation by curcumin: Implications for cancer therapy. J Cell Physiol 234: 12537-12550, 2019.

35. Harini L, Srivastava S, Gnanakumar GP, Karthikeyan B, Ross C, Krishnakumar V, Kannan VR, Sundar K and Kathiresan T: An ingenious non-spherical mesoporous silica nanoparticle cargo with curcumin induces mitochondria-mediated apoptosis in breast cancer (MCF-7) cells. Oncotarget 10: 1193-1208, 2019.

36. Moustakas A and Heldin CH: Non-Smad TGF-beta signals. J Cell Sci 118: 3573-3584, 2005.

37. Wang X, Hang Y, Liu J, Hou Y, Wang $N$ and Wang M: Anticancer effect of curcumin inhibits cell growth through miR-21/PTEN/Akt pathway in breast cancer cell. Oncol Lett 13: 4825-4831, 2017.

38. Chen YY, Lin YJ, Huang WT, Hung CC, Lin HY, Tu YC, Liu DM, Lan SJ and Sheu MJ: Demethoxycurcumin-loaded chitosan nanoparticle downregulates DNA repair pathway to improve cisplatin-induced apoptosis in non-small cell lung cancer. Molecules 23: pii: E3217, 2018.

39. Wang C, Song X, Shang M, Zou W, Zhang M, Wei H and Shao H: Curcumin exerts cytotoxicity dependent on reactive oxygen species accumulation in non-small-cell lung cancer cells. Future Oncol 15: 1243-1253, 2019.

40. Tan C, Hu W, He Y, Zhang Y, Zhang G, Xu Y and Tang J: Cytokine-mediated therapeutic resistance in breast cancer. Cytokine 108: 151-159, 2018

41. de Campos PS, Matte BF, Diel LF, Jesus LH, Bernardi L, Alves AM, Rados PV and Lamers ML: Low doses of curcuma longa modulates cell migration and cell-cell adhesion. Phytother Res 31: 1433-1440, 2017.

42. Cao MT, Liu HF, Liu ZG, Xiao P, Chen JJ, Tan Y, Jiang XX, Jiang ZC, Qiu Y, Huang HJ, et al: Curcumin downregulates the expression of Snail via suppressing Smad2 pathway to inhibit TGF- $\beta 1$-induced epithelial-mesenchymal transitions in hepatoma cells. Oncotarget 8: 108498-108508, 2017.

43. Li W, Ma Z, Ma J, Li X, Xu Q, Duan W, Chen X, Lv Y, Zhou S, Wu E, et al: Hydrogen peroxide mediates hyperglycemia-induced invasive activity via ERK and p38 MAPK in human pancreatic cancer. Oncotarget 6: 31119-31133, 2015.

44. Cao L, Liu J, Zhang L, Xiao X and Li W: Curcumin inhibits $\mathrm{H} 2 \mathrm{O} 2$-induced invasion and migration of human pancreatic cancer via suppression of the ERK/NF- $\kappa \mathrm{B}$ pathway. Oncol Rep 36: 2245-2251, 2016.

45. Jászai J and Schmidt MHH: Trends and challenges in tumor anti-angiogenic therapies. Cells 8: pii: E1102, 2019.

46. Lin Z, Zhang Q and Luo W: Angiogenesis inhibitors as therapeutic agents in cancer: Challenges and future directions. Eur J Pharmacol 793: 76-81, 2016.

47. Norooznezhad AH and Norooznezhad F: Cannabinoids: Possible agents for treatment of psoriasis via suppression of angiogenesis and inflammation. Med Hypotheses 99: 15-18, 2017.

48. Saberi-Karimian M, Katsiki N, Caraglia M, Boccellino M, Majeed M and Sahebkar A: Vascular endothelial growth factor: An important molecular target of curcumin. Crit Rev Food Sci Nutr 59: 299-312, 2019

49. Jiao D, Wang J, Lu W, Tang X, Chen J, Mou H and Chen QY: Curcumin inhibited HGF-induced EMT and angiogenesis through regulating c-Met dependent $\mathrm{PI} 3 \mathrm{~K} / \mathrm{Akt} / \mathrm{mTOR}$ signaling pathways in lung cancer. Mol Ther Oncolytics 3: 16018, 2016.

50. Liang C, Shi S, Meng Q, Liang D, Ji S, Zhang B, Qin Y, Xu J, $\mathrm{Ni} \mathrm{Q}$ and $\mathrm{Yu} \mathrm{X}$ : Complex roles of the stroma in the intrinsic resistance to gemcitabine in pancreatic cancer: Where we are and where we are going. Exp Mol Med 49: e406, 2017.

51. Su P, Yang Y, Wang G, Chen X and Ju Y: Curcumin attenuates resistance to irinotecan via induction of apoptosis of cancer stem cells in chemoresistant colon cancer cells. Int J Oncol 53 : 1343-1353, 2018

52. Zhou QM, Sun Y, Lu YY, Zhang H, Chen QL and Su SB: Curcumin reduces mitomycin $C$ resistance in breast cancer stem cells by regulating Bcl-2 family-mediated apoptosis. Cancer Cell Int 17: 84, 2017.

53. Zhang J, Liu J, Xu X and Li L: Curcumin suppresses cisplatin resistance development partly via modulating extracellular vesicle-mediated transfer of MEG3 and miR-214 in ovarian cancer. Cancer Chemother Pharmacol 79: 479-87, 2017.

54. Yang H, Kong W, He L, Zhao JJ, O'Donnell JD, Wang J, Wenham RM, Coppola D, Kruk PA, Nicosia SV and Cheng JQ MicroRNA expression profiling in human ovarian cancer: miR-214 induces cell survival and cisplatin resistance by targeting PTEN. Cancer Res 68: 425-433, 2008.
55. Batista S, Gregório AC, Hanada Otake A, Couto N and Costa-Silva B: The gastrointestinal tumor microenvironment: An updated biological and clinical perspective. J Oncol 2019: 6240505, 2019.

56. O'Donnell JS, Teng MWL and Smyth MJ: Cancer immunoediting and resistance to T cell-based immunotherapy. Nat Rev Clin Oncol 16: 151-167, 2019

57. Wattenberg MM and Beatty GL: Overcoming immunotherapeutic resistance by targeting the cancer inflammation cycle. Semin Cancer Biol, Jan 15, 2020 (Epub ahead of print).

58. Dunn GP, Koebel CM and Schreiber RD: Interferons, immunity and cancer immunoediting. Nat Rev Immunol 6: 836-848, 2006.

59. Lee JH, Choi SY, Jung NC, Song JY, Seo HG, Lee HS and Lim DS: The effect of the tumor microenvironment and tumor-derived metabolites on dendritic cell function. J Cancer 11: 769-775, 2020.

60. Galland S and Stamenkovic I: Mesenchymal stromal cells in cancer: A review of their immunomodulatory functions and dual effects on tumor progression. J Pathol, Oct 14, 2019 (Epub ahead of print).

61. Swann JB and Smyth MJ: Immune surveillance of tumors. J Clin Invest 117: 1137-1146, 2007.

62. Das T, Sa G, Paszkiewicz-Kozik E, Hilston C, Molto L, Rayman P, Kudo D, Biswas K, Bukowski RM, Finke JH and Tannenbaum CS: Renal cell carcinoma tumors induce $\mathrm{T}$ cell apoptosis through receptor-dependent and receptor-independent pathways. J Immunol 180: 4687-4696, 2008.

63. Snyder JT, Alexander-Miller MA, Berzofskyl JA and Belyakov IM: Molecular mechanisms and biological significance of CTL avidity. Curr HIV Res 1: 287-294, 2003.

64. Chen MC, Pangilinan CR and Lee CH: Salmonella breaks tumor immune tolerance by downregulating tumor programmed death-ligand 1 expression. Cancers (Basel) 12: pii: E57, 2019.

65. Sa G, Das T, Moon C, Hilston CM, Rayman PA, Rini BI, Tannenbaum CS and Finke JH: GD3, an overexpressed tumor-derived ganglioside, mediates the apoptosis of activated but not resting T cells. Cancer Res 69: 3095-3104, 2009.

66. Rabinovich GA, Gabrilovich D and Sotomayor EM: Immunosuppressive strategies that are mediated by tumor cells. Annu Rev Immunol 25: 267-296, 2007.

67. Geng Y, Liu J, Xie Y, Jiang H, Zuo K, Li T and Liu Z: Trichostatin A promotes GLI1 degradation and P21 expression in multiple myeloma cells. Cancer Manag Res 10: 2905-2914, 2018.

68. Wang Y, Zhou X, Song Y, Ji X, Zhang A, Zhang G and Gao Z: The mismatch repair gene hPMS1 (human postmeiotic segregation1) is down regulated in oral squamous cell carcinoma. Gene 524: 28-34, 2013.

69. Fratta E, Coral S, Covre A, Parisi G, Colizzi F, Danielli R, Nicolay HJ, Sigalotti L and Maio M: The biology of cancer testis antigens: Putative function, regulation and therapeutic potential. Mol Oncol 5: 164-182, 2011.

70. Liu M, Zhou J, Chen Z and Cheng AS: Understanding the epigenetic regulation of tumours and their microenvironments: Opportunities and problems for epigenetic therapy. J Pathol 241: 10-24, 2017

71. Dunn J and Rao S: Epigenetics and immunotherapy: The current state of play. Mol Immunol 87: 227-239, 2017.

72. Rosenthal R, Cadieux EL, Salgado R, Bakir MA, Moore DA, Hiley CT, Lund T, Tanić M, Reading JL, Joshi K, et al: Neoantigen-directed immune escape in lung cancer evolution. Nature 567: 479-485, 2019.

73. Dunn GP, Bruce AT, Ikeda H, Old LJ and Schreiber RD: Cancer immunoediting: From immunosurveillance to tumor escape. Nat Immunol 3: 991-998, 2002

74. Mori S, Jewett A, Murakami-Mori K, Cavalcanti M and Bonavida B: The participation of the Fas-mediated cytotoxic pathway by natural killer cells is tumor-cell-dependent. Cancer Immunol Immunother 44: 282-290, 1997.

75. Takeda K, Hayakawa Y, Smyth MJ, Kayagaki N, Yamaguchi N, Kakuta S, Iwakura Y, Yagita $\mathrm{H}$ and Okumura K: Involvement of tumor necrosis factor-related apoptosis-inducing ligand in surveillance of tumor metastasis by liver natural killer cells. Nat Med 7: 94-100, 2001.

76. Street SE, Cretney E and Smyth MJ: Perforin and interferon-gamma activities independently control tumor initiation, growth, and metastasis. Blood 97: 192-197, 2001

77. MacKie RM, Reid R and Junor B: Fatal melanoma transferred in a donated kidney 16 years after melanoma surgery. $\mathrm{N}$ Engl J Med 348: 567-568, 2003. 
78. Li W, Wang H, Ma Z, Zhang J, Ou-Yang W, Qi Y and Liu J: Multi-omics analysis of microenvironment characteristics and immune escape mechanisms of hepatocellular carcinoma. Front Oncol 9: 1019, 2019.

79. Kim R, Emi M and Tanabe K: Cancer immunoediting from immune surveillance to immune escape. Immunology 121: 1-14, 2007.

80. Itakura E, Huang RR, Wen DR, Paul E, Wünsch PH and Cochran AJ: IL-10 expression by primary tumor cells correlates with melanoma progression from radial to vertical growth phase and development of metastatic competence. Mod Pathol 24: 801-809, 2011

81. Brody JR, Costantino CL, Berger AC, Sato T, Lisanti MP, Yeo CJ, Emmons RV and Witkiewicz AK: Expression of indoleamine 2,3-dioxygenase in metastatic malignant melanoma recruits regulatory $\mathrm{T}$ cells to avoid immune detection and affects survival. Cell Cycle 8: 1930-1934, 2009.

82. Zou W: Immunosuppressive networks in the tumour environment and their therapeutic relevance. Nat Rev Cancer 5 : 263-274, 2005

83. Bhattacharyya S, Mandal D, Sen GS, Pal S, Banerjee S, Lahiry L, Finke JH, Tannenbaum CS, Das T and Sa G: Tumor-induced oxidative stress perturbs nuclear factor-kappaB activity-augmenting tumor necrosis factor-alpha-mediated T-cell death: Protection by Curcumin. Cancer Res 67: 362-370, 2007.

84. Bhattacharyya S, Md Sakib Hossain D, Mohanty S, Sankar Sen G, Chattopadhyay S, Banerjee S, Chakraborty J, Das K, Sarkar D, Das T and Sa G: Curcumin reverses T cell-mediated adaptive immune dysfunctions in tumor-bearing hosts. Cell Mol Immunol 7: 306-315, 2010.

85. $\mathrm{Xu} \mathrm{B}, \mathrm{Yu} \mathrm{L}$ and Zhao LZ: Curcumin up regulates $\mathrm{T}$ helper 1 cells in patients with colon cancer. Am J Transl Res 9: 1866-1875, 2017.

86. Zou JY, Su CH, Luo HH, Lei YY, Zeng B, Zhu HS and Chen ZG: Curcumin converts Foxp3+ regulatory T cells to T helper 1 cells in patients with lung cancer. J Cell Biochem 119: 1420-1428, 2018.

87. Milano F, Mari L, van de Luijtgaarden W, Parikh K, Calpe S and Krishnadath KK: Nano-curcumin inhibits proliferation of esophageal adenocarcinoma cells and enhances the $\mathrm{T}$ cell mediated immune response. Front Oncol 3: 137, 2013

88. Rosenberg SA, Restifo NP, Yang JC, Morgan RA and Dudley ME: Adoptive cell transfer: A clinical path to effective cancer immunotherapy. Nat Rev Cancer 8: 299-308, 2008

89. Hawkins RE, Gilham DE, Debets R, Eshhar Z, Taylor N, Abken H and Schumacher TN, ATTACK Consortium: Development of adoptive cell therapy for cancer: A clinical perspective. Hum Gene Ther 21: 665-672, 2010.

90. Chang YF, Chuang HY, Hsu CH, Liu RS, Gambhir SS and Hwang JJ: Immunomodulation of curcumin on adoptive therapy with $\mathrm{T}$ cell functional imaging in mice. Cancer Prev Res (Phila) 5: 444-452, 2012.

91. Luo F, Song X, Zhang Y and Chu Y: Low-dose curcumin leads to the inhibition of tumor growth via enhancing CTL-mediated antitumor immunity. Int Immunopharmacol 11: 1234-1240, 2011.

92. Lu Y, Miao L, Wang Y, Xu Z, Zhao Y, Shen Y, Xiang G and Huang L: Curcumin micelles remodel tumor microenvironment and enhance vaccine activity in an advanced melanoma model. Mol Ther 24: 364-374, 2016.

93. Lin Y, Xu J and Lan H: Tumor-associated macrophages in tumor metastasis: Biological roles and clinical therapeutic applications. J Hematol Oncol 12: 76, 2019.

94. Kim DH, Lee HG and Choi JM: Curcumin Elevates $\mathrm{T}_{\mathrm{FH}}$ cells and germinal center B cell response for antibody production in mice. Immune Netw 19: e35, 2019.

95. Shevach EM: Application of IL-2 therapy to target T regulatory cell function. Trends Immunol 33: 626-632, 2012.

96. Oh JG, Hwang DJ and Heo TH: Direct regulation of IL-2 by curcumin. Biochem Biophys Res Commun 495: 300-305, 2018.

97. Shiri S, Alizadeh AM, Baradaran B, Farhanghi B, Shanehbandi D, Khodayari S, Khodayari $\mathrm{H}$ and Tavassoli A: Dendrosomal curcumin suppresses metastatic breast cancer in mice by changing $\mathrm{m} 1 / \mathrm{m} 2$ macrophage balance in the tumor microenvironment. Asian Pac J Cancer Prev 16: 3917-3922, 2015.

98. Xie Q, Yang Z, Huang X, Zhang Z, Li J, Ju J, Zhang H and Ma J: Ilamycin $\mathrm{C}$ induces apoptosis and inhibits migration and invasion in triple-negative breast cancer by suppressing IL-6/ STAT3 pathway. J Hematol Oncol 12: 60, 2019.
99. Singh M, Ramos I, Asafu-Adjei D, Quispe-Tintaya W, Chandra D, Jahangir A, Zang X, Aggarwal BB and Gravekamp C: Curcumin improves the therapeutic efficacy of Listeria(at)-Mage-b vaccine in correlation with improved T-cell responses in blood of a triple-negative breast cancer model 4T1. Cancer Med 2: 571-582, 2013.

100. Bill MA, Bakan C, Benson DM Jr, Fuchs J, Young G and Lesinski GB: Curcumin induces proapoptotic effects against human melanoma cells and modulates the cellular response to immunotherapeutic cytokines. Mol Cancer Ther 8: 2726-2735, 2009.

101. Jin H, Jia Y, Yao Z, Huang J, Hao M, Yao S, Lian N, Zhang F, Zhang C, Chen X, et al: Hepatic stellate cell interferes with NK cell regulation of fibrogenesis via curcumin induced senescence of hepatic stellate cell. Cell Signal 33: 79-85, 2017.

102.Zhang HG, Kim H, Liu C, Yu S, Wang J, Grizzle WE, Kimberly RP and Barnes S: Curcumin reverses breast tumor exosomes mediated immune suppression of NK cell tumor cytotoxicity. Biochim Biophys Acta 1773: 1116-1123, 2007.

103. Lee $\mathrm{HH}$ and Cho $\mathrm{H}$ : Improved anti-cancer effect of curcumin on breast cancer cells by increasing the activity of natural killer cells. J Microbiol Biotechnol 28: 874-882, 2018.

104. Halder RC, Almasi A, Sagong B, Leung J, Jewett A and Fiala M: Curcuminoids and $\omega-3$ fatty acids with anti-oxidants potentiate cytotoxicity of natural killer cells against pancreatic ductal adenocarcinoma cells and inhibit interferon $\gamma$ production. Front Physiol 22: 6: 129, 2015.

105. Mills CD, Kincaid K, Alt JM,Heilman MJ and Hill AM: M-1/M-2 macrophages and the Th1/Th2 paradigm. J Immunol 164: 6166-6173, 2000.

106. Murray PJ, Allen JE, Biswas SK, Fisher EA, Gilroy DW, Goerdt S, Gordon S, Hamilton JA, Ivashkiv LB, Lawrence T, et al: Macrophage activation and polarization: Nomenclature and experimental guidelines. Immunity 41: 14-20, 2014

107. Mukherjee S, Hussaini R, White R, Atwi D, Fried A, Sampat S, Piao L, Pan Q and Banerjee P: TriCurin, a synergistic formulation of curcumin, resveratrol, and epicatechin gallate, repolarizes tumor-associated macrophages and triggers an immune response to cause suppression of HPV+ tumors. Cancer Immunol Immunother 67: 761-774, 2018

108. Mukherjee S, Fried A, Hussaini R, White R, Baidoo J, Yalamanchi S and Banerjee P: Phytosomal curcumin causes natural killer cell-dependent repolarization of glioblastoma (GBM) tumor-associated microglia/macrophages and elimination of GBM and GBM stem cells. J Exp Clin Cancer Res 37: $168,2018$.

109. Mukherjee S, Baidoo JNE, Sampat S, Mancuso A, David L, Cohen LS, Zhou S and Banerjee P: Liposomal TriCurin, a synergistic combination of curcumin, epicatechin gallate and resveratrol, repolarizes tumor-associated microglia/macrophages, and eliminates glioblastoma (GBM) and GBM stem cells. Molecules 23: pii: E201, 2018

110. Kuttan R, Sudheeran PC and Josph CD: Turmeric and curcumin as topical agents in cancer therapy. Tumori 73: 29-31, 1987.

111. Pastorelli D, Fabricio ASC, Giovanis P, D'Ippolito S, Fiduccia P, Soldà C, Buda A, Sperti C, Bardini R, Da Dalt G, et al: Phytosome complex of curcumin as complementary therapy of advanced pancreatic cancer improves safety and efficacy of gemcitabine: Results of a prospective phase II trial. Pharmacol Res 132: 72-79, 2018

112. James MI, Iwuji C, Irving G, Karmokar A, Higgins JA, Griffin-Teal N, Thomas A, Greaves P, Cai H, Patel SR, et al: Curcumin inhibits cancer stem cell phenotypes in ex vivo models of colorectal liver metastases, and is clinically safe and tolerable in combination with FOLFOX chemotherapy. Cancer Lett 364: 135-141, 2015.

113. Mahammedi H,PlanchatE, Pouget M, Durando X, Curé H, Guy L, Van-Praagh I, Savareux L, Atger M, Bayet-Robert M, et al: The New Combination docetaxel, prednisone and curcumin in patients with castration-resistant prostate cancer: A pilot phase II study. Oncology 90: 69-78, 2016.

114. Ryan JL, Heckler CE, Ling M, Katz A, Williams JP, Pentland AP and Morrow GR: Curcumin for radiation dermatitis: A randomized, double-blind, placebo-controlled clinical trial of thirty breast cancer patients. Radiat Res 180: 34-43, 2013

115. Dhillon N, Aggarwal BB, Newman RA, Wolff RA, Kunnumakkara AB, Abbruzzese JL, Ng CS, Badmaev V and Kurzrock R: Phase II trial of curcumin in patients with advanced pancreatic cancer. Clin Cancer Res 14: 4491-4499, 2008. 
116. Saif MW: Is there a role for herbal medicine in the treatment of pancreatic cancer? Highlights from the '44th ASCO Annual Meeting'. Chicago, IL, USA. May 30-June 3, 2008. JOP 9: 403-407, 2008

117. Epelbaum R, Schaffer M, Vizel B, Badmaev V and Bar-Sela G: Curcumin and gemcitabine in patients with advanced pancreatic cancer. Nutr Cancer 62: 1137-1141, 2010.

118. Kanai M, Yoshimura K, Asada M, Imaizumi A, Suzuki C, Matsumoto S, Nishimura T, Mori Y, Masui T, Kawaguchi Y, et al: A phase I/II study of gemcitabine-based chemotherapy plus curcumin for patients with gemcitabine-resistant pancreatic cancer. Cancer Chemother Pharmacol 68: 157-164, 2011.

119. Wan Y, Liang Y, Liang F, Shen N, Shinozuka K, Yu JT, Ran C, Quan Q, Tanzi RE and Zhang C: A curcumin analog reduces levels of the Alzheimer's disease-associated amyloid- $\beta$ protein by modulating A $\beta \mathrm{PP}$ processing and autophagy. J Alzheimers Dis 72: 761-771, 2019.

120. Rezzani R, Franco C and Rodella LF: Curcumin as a therapeutic strategy in liver diseases. Nutrients 11: pii: E2498, 2019.

121. Fleenor BS, Carlini NA and Campbell MS: Curcumin and arterial function in health and disease: Impact on oxidative stress and inflammation. Curr Opin Clin Nutr Metab Care 22: 459-464, 2019.

122. Zhao S, Pi C, Ye Y, Zhao L and Wei Y: Recent advances of analogues of curcumin for treatment of cancer. Eur J Med Chem 180: 524-535, 2019.
123. Tønnesen HH, Másson M and Loftsson T: Studies of curcumin and curcuminoids. XXVII. Cyclodextrin complexation: Solubility, chemical and photochemical stability. Int J Pharm 244: 127-135, 2002.

124. Li X, Uehara S, Sawangrat K, Morishita M, Kusamori K, Katsumi H, Sakane T and Yamamoto A: Improvement of intestinal absorption of curcumin by cyclodextrins and the mechanisms underlying absorption enhancement. Int $\mathrm{J}$ Pharm 535: 340-349, 2018.

125. Bisht S, Feldmann G, Soni S, Ravi R, Karikar C, Maitra A and Maitra A: Polymeric nanoparticle-encapsulated curcumin ('nanocurcumin'): A novel strategy for human cancer therapy. J Nanobiotechnology 5: 3, 2007.

126. Han W, Xie B, Li Y, Shi L, Wan J, Chen X and Wang H: Orally deliverable nanotherapeutics for the synergistic treatment of colitis-associated colorectal cancer. Theranostics 9: 7458-7473, 2019.

127. Guo F, Fu Q, Jin C, Ji X, Yan Q, Yang Q, Wu D, Gao Y, Hong W, Li A and Yang G: Dual functional matrix metalloproteinase-responsive curcumin-loaded nanoparticles for tumor-targeted treatment. Drug Deliv 26: 1027-1038, 2019.

This work is licensed under a Creative Commons Attribution-NonCommercial-NoDerivatives 4.0 International (CC BY-NC-ND 4.0) License. 